\title{
Acúmulo de Massa Seca e Macronutrientes por Plantas de Glycine max E Richardia brasiliensis ${ }^{1}$
}

\author{
Accumulation of Biomass and Macronutrients by Glycine max and Richardia brasiliensis
}

\author{
PEDRINHO JÚNIOR, A.F.F. ${ }^{2}$, BIANCO, S. ${ }^{3}$ e PITELLI, R.A. ${ }^{3}$
}

\begin{abstract}
RESUMO - Foram realizados dois experimentos, em condições de casa de vegetação, no Departamento de Biologia Aplicada à Agropecuária da FCAV-UNESP de Jaboticabal, objetivando-se determinar o acúmulo de massa seca, assim como a distribuição e o acúmulo de macronutrientes durante os ciclos de vida de plantas de soja cultivar BR16, no período de outubro de 2000 a fevereiro de 2001, e de Richardia brasiliensis (poaia-branca), uma planta daninha de elevada importância para esta cultura no Brasil, especialmente em áreas de plantio direto, no período de outubro de 1998 a fevereiro de 1999. Os estudos foram realizados em delineamento experimental inteiramente casualizado, com quatro repetições. Quatro plantas cresceram em vasos com capacidade de sete litros, preenchidos com areia de rio lavada, peneirada e irrigada diariamente com solução nutritiva. Os tratamentos foram representados pelas épocas de amostragem, realizadas a intervalos de 14 dias, a saber: 22, $36,50,64,78,92,106,120,134,148,162$ e 176 dias após a emergência (DAE) das plantas de $R$. brasiliensis; e 21, 35, 49, 63, 77, 91, 105 e 119 DAE das plantas de soja cv. BR-16 (precoce). Em ambas as plantas, as folhas tiveram a maior partição de biomassa durante sete semanas. Para este dado, a partição foi maior para as estruturas reprodutivas em soja e nos caules para a poaia-branca. O ponto de máximo acúmulo teórico de massa seca deu-se aos 104 DAE para a soja (36,6 g por planta) e aos 146 DAE para a poaia-branca (16,4 g por planta). Da emergência até aos $50 \mathrm{DAE}$ as folhas apresentaram maior participação no acúmulo de massa seca, nas duas espécies. Após 50 DAE notou-se, em ambas as espécies, uma inversão na representatividade das folhas por caules, para a espécie daninha, e por caules e posteriormente por estruturas reprodutivas, para a cultura. A taxa de absorção diária dos macronutrientes atingiu maiores valores entre 69 e 87 DAE para a soja e entre 106 a $111 \mathrm{DAE}$ para a planta daninha. Levando em conta a média dos valores de pontos de inflexão observados para a cultura da soja, aos 78 DAE uma planta de soja acumula teoricamente 25,9 g de massa seca; 615,5 mg de N; 77,2 mg de P; 538,6 mg de K; 535,0 mg de Ca; 171,5 mg de Mg; e $39,5 \mathrm{mg}$ de $\mathrm{S}$. Para o mesmo período, uma planta de $R$. brasiliensis acumula teoricamente 3,7 g de massa seca; 50,8 mg de N; 3,2 mg de P; 104,4 mg de K; 127,8 mg de Ca; 18,8 mg de $\mathrm{Mg}$; e 3,7 mg de S.
\end{abstract}

Palavras-chave: poaia-branca, soja, biomassa, nutrição mineral, análise de crescimento.

AABSTRACT - Two greenhouse trials were carried out under greenhouse conditionsat the Department of Agricultural Biology at FCAV-UNESP in Jaboticabal, SP, Brazil to study tbiomass accumulation as well as macronutrient distribution and accumulation during the life cycle of the soybean cultivar BR 16 from October 2000 to February 2001, and Richardia brasiliensis (Brazilian pusley), from October 1998 to February 1999. Brazilian pusley is one of the most important weeds in the mid western soybean growing area, mainly under no tillage system. The studies were conducted in a randomized complete design with four replications. Four plants

1 Recebido para publicação em 24.6.2003 e na forma revisada em 5.3.2004.

Parte da dissertação de Mestrado do primeiro autor.

2 Pós-Graduando em Produção Vegetal pela FCAV-UNESP de Jaboticabal, <aimar@zipmail.com.br>; ${ }^{3}$ Prof. Dr. do Dep. de Biologia Aplicada à Agropecuária da Universidade Estadual Paulista - FCAVJ-UNESP, Via de Acesso Prof. Paulo D. Castellane Km 5, 14860-000 Jaboticabal-SP, <sbianco@fcav.unesp.br>e <pitelli@fcav.unesp.br>. 
were grown in seven liter pots filled with sandy substrate irrigated daily with a nutritive solution. The treatments were represented by timing of sampling, performed at 14 day intervals, 22, 36, $50,64,78,92,106,120,134,148,162$ and 176 days after emergence (DAE) of $\boldsymbol{R}$. brasiliensis plants; and 21, 35, 49, 63, 77, 91, 105 and 119 DAE of the soybean plants BR-16 (early maturity) For both plants, the leaves had the highest biomass partition during seven weeks. For these data, partition was higher in reproductive structures in soybean and in the stems for Brazilian pusley. The maximumcritical biomass accumulation was estimated at 104 days for soybean (36.6 $\mathrm{g} \mathrm{plant}^{1}$ ) and at 146 days for $\boldsymbol{R}$. brasiliensis (16.4 $\mathrm{g}$ planta $\left.^{1}\right)$. From emergence up to $50 \mathrm{DAE}$, the leaves presented higher participation in biomass accumulation, in both species. After $50 \mathrm{DAE}$, it was observed in both species an inversion in leaf representativity per shoots, for the weed species and per shoots and later per reproductive structures, for thecrop. The maximumdaily macronutrient uptake ratewas achieved between 69 and 87 days in soybean and 106 and 111 DAE in R. brasiliensis. Considering of the inflexion point average observed for the soybean culture, it is possible to estimate that, at $78 \mathrm{DAE}$, this plant theoretically accumulates $25.9 \mathrm{gof}$ dry weight; $615.6 \mathrm{mg}$ oN; $77.2 \mathrm{mg} \mathrm{P;} 538.6 \mathrm{mg} \mathrm{K} ; 535.0 \mathrm{mg} \mathrm{Ca;} 171.5 \mathrm{mg}$ $\mathrm{Mg}$ and $39,5 \mathrm{mg} \mathrm{S}$. In the same period, one razilian pusley plant accumulates $3.7 \mathrm{~g}$ dry weight; $50.8 \mathrm{mg} \mathrm{N}$; $3.2 \mathrm{mg} \mathrm{P;} 104.4 \mathrm{mg} \mathrm{K} ; 127.8 \mathrm{mg} \mathrm{Ca} ; 18.8 \mathrm{mg} \mathrm{Mg}$ and $3.7 \mathrm{mg} \mathrm{oS}$.

Key words: Soybean, Brazilian pusley, weeds, plant nutrition, ecophysiology.

\section{INTRODUÇÃO}

A importância nutricional da soja para a humanidade é relevante, pelo fato de ser uma excelente fonte protéica e poder ser cultivada em quase todas as regiões do mundo. O Brasil, atualmente, ocupa a posição de segundo maior produtor e exportador de soja do mundo, com uma área plantada de doze milhões de hectares por ano e participação com mais de $27 \%$ da soja produzida mundialmente na safra de 2001/2002 (Agrianual, 2000).

Na literatura internacional é relatado que as plantas daninhas são, na maioria das vezes, as maiores responsáveis por reduções de produtividade da cultura da soja, com danos que ultrapassam os causados por pragas e patógenos.

Blanco et al. (1973, 1978) verificaram prejuízos na produtividade da soja variando de 42 a 95\%, dependendo das populações de plantas daninhas presentes. Durigan (1983) comparou a produtividade dos cultivares Santa Rosa e IAC-2, cultivados em dois tipos de solo, observando reduções de 70,1 e 73,4\% em Latossolo Roxo e 57,0 e 57,4\% em Latossolo Vermelho-Escuro, respectivamente, quando mantidos por todo o ciclo em convivência com a comunidade infestante. Nesse mesmo período de convivência, foram relatadas perdas de
69,4\% para o cultivar ENGOPA 304 (Barros et al., 1992), de 52,6\% para o cultivar Paraná (Carvalho, 1993) e de 56,4\% para o cultivar IAC-11 (Carvalho \& Velini, 2001).

As perdas de produção se devem às interferências decorrentes da presença das plantas daninhas na lavoura. Dentre as formas de interferência direta, Pitelli (1985) destaca a competição pelo espaço e pelos recursos de crescimento, como água, luz e nutrientes.

Na cultura da soja, uma das plantas problemáticas é a Richardia brasilensis (poaia-branca), uma Rubiácea herbácea de hábito geralmente prostrado, podendo chegar a até $50 \mathrm{~cm}$ de altura. Essa importância se dá, principalmente, pela sua presença marcante nas regiões agrícolas do Centro-Oeste, Sul e Sudeste e sua facilidade em se adaptar aos diferentes sistemas de plantio (direto e convencional), com considerável germinação durante todo o verão. Com ciclo anual, é considerada problemática por competir com a cultura e ser de difícil controle (Kissmann, 1995). Esta planta é pouco conhecida em termos de crescimento, desenvolvimento e exigências nutricionais, não sendo encontradas referências sobre o assunto na literatura consultada.

Alguns estudos foram realizados visando conhecer as curvas de crescimento e de acúmulo de nutrientes por espécies como 
Commelina benghalensis (Rodrigues, 1992), Acanthospermum hispidum (Andreani Junior, 1995) e Rottboelia exaltata (Barbosa Junior, 2001). Esses estudos foram realizados em casa de vegetação e não incluíram uma espécie cultivada, tornando difícil fazer extrapolações comparativas. Assim, com o presente trabalho, objetivou-se estudar o acúmulo e a distribuição de massa seca e de macronutrientes por Richardia brasiliensis e pela soja, cultivadas em condições similares, mas não simultâneas, a fim de possibilitar comparações.

\section{MATERIAL E MÉTODOS}

Foram realizados dois experimentos em casa de vegetação do Departamento de Biologia Aplicada à Agropecuária da Faculdade de Ciências Agrárias e Veterinárias - UNESP de Jaboticabal, no período de outubro de 1998 a fevereiro de 1999, para Richardia brasiliensis, e de outubro de 2000 a fevereiro de 2001, para a cultura da soja. No primeiro experimento, estudou-se o acúmulo de massa seca, alocação e acúmulo de macronutrientes por plantas de $R$. brasiliensis e, no segundo, por plantas de Glycine $\max \mathrm{cv}$. BR-16, utilizando-se como substrato areia de rio lavada e como fonte de nutrientes solução nutritiva completa de Hoagland \& Arnon (1950).

O substrato foi peneirado em tamis de $5 \mathrm{~mm}$ e acondicionado em vasos de plástico com capacidade para sete litros, perfurados e conectados, através de mangueiras plásticas de $1,0 \mathrm{~cm}$ de diâmetro e $75 \mathrm{~cm}$ de comprimento, a frascos de vidro escuro com capacidade de um litro. A finalidade era coletar a solução lixiviada nas irrigações, com posterior retorno desta aos vasos. Foram plantadas 50 sementes/vaso de $R$. brasiliensis e 20 sementes/vaso de G. max. Em ambos os experimentos, quando as mudas atingiram dois pares de folhas verdadeiras totalmente expandidas, foi efetuado um desbaste, deixando-se quatro plantas por vaso.

Os vasos foram irrigados com a solução nutritiva completa de Hoagland \& Arnon (1950), recebendo $25 \%$ da concentração original até a primeira amostragem e, depois, 50\% até o final da fase experimental. Os vasos receberam volume de solução suficiente para iniciar a percolação para os vidros coletores. O número de irrigações diárias deu-se em função do crescimento das plantas e da demanda de água pelo sistema.

Os vasos foram distribuídos aleatoriamente na casa de vegetação e suas posições foram alteradas semanalmente, também aleatoriamente, permitindo assim a casualização das parcelas. O delineamento experimental utilizado foi o inteiramente casualizado, com quatro repetições. Foram utilizados doze e oito épocas de amostragem para $R$. brasiliensis e para a soja, respectivamente, devido ao ciclo de desenvolvimento das plantas.

Os tratamentos foram representados pelas épocas de amostragem, realizadas a intervalos de 14 dias, a saber: $22,36,50,64,78,92,106$, $120,134,148,162$ e 176 dias após a emergência (DAE) das plantas de $R$. brasiliensis; e $21,35,49,63,77,91,105$ e 119 DAE, para soja.

Nas avaliações, as plantas foram separadas em raiz, caule, folhas e estruturas reprodutivas. A seguir, esses materiais foram lavados na seguinte seqüência: rápida imersão em solução diluída de detergente neutro, lavagem e imersão em água destilada e, finalmente, imersão em água deionizada.

Após a lavagem, as diferentes partes das plantas foram acondicionadas em sacos de papel devidamente etiquetados e perfurados, para posterior secagem em estufa de circulação forçada de ar, a $60-70{ }^{\circ} \mathrm{C}$, por 96 horas. A determinação da massa seca foi efetuada em balança eletrônica com precisão de 0,001 g. Após a pesagem, o material foi moído em micromoinho tipo Willey, malha 20, e armazenado em frascos de vidro hermeticamente fechados, sendo posteriormente analisado quanto ao teor de macronutrientes.

A análise de nitrogênio $(\mathrm{N})$ total foi efetuada pela metodologia do semi-Microkjeldahl e a do fósforo (P) pela metodologia do ácido fosfovanadatomolíbdico. A determinação de potássio (K), cálcio (Ca) e magnésio $(\mathrm{Mg})$ foi feita por espectrofotometria de absorção atômica, enquanto o enxofre (S) foi determinado pelo método turbidimétrico.

Através da observação dos valores encontrados no teor de cada nutriente ao longo do ciclo da planta, foi possível determinar a amplitude de variação do teor total de cada 
nutriente; para isso, foram observados o maior e o menor valor de teor total apresentados pela somatória dos teores de cada nutriente encontrado nas diferentes partes da planta.

Os acúmulos de nutrientes para cada uma das partes das plantas foram conseguidos multiplicando-se o teor do nutriente pela massa seca correspondente. O acúmulo total foi obtido através da somatória dos acúmulos das diferentes partes da planta, enquanto o teor total da planta foi obtido pela relação entre o acúmulo total e a massa seca total da planta.

Para cálculo do acúmulo total dos macronutrientes, utilizou-se a integral sob a equação exponencial ajustada, $\mathrm{Y}=\exp \left(\mathrm{a}+\mathrm{bx}+\mathrm{cx}^{2}\right)$, sendo $\mathrm{Y}=$ acúmulo do nutriente $\mathrm{e} \mathrm{x}=$ dias após a emergência, ajustando-se curvas de crescimento em função dos dias do ciclo de vida da planta, refletindo um esboço comportamental de cada espécie em relação à massa seca e ao nutriente estudado. Para a escolha da equação de regressão foram considerados a lógica do fenômeno biológico do crescimento e o valor do coeficiente de determinação. Os pontos de inflexão e de máximo da curva foram determinados pelas derivadas (primeira e segunda) da equação ajustada aos dados obtidos.

\section{RESULTADOS E DISCUSSÃO}

A poaia-branca foi mais precoce que a soja na alocação de recursos para estruturas reprodutivas (Figura 1). Desde os 50 DAE, ela manteve a alocação de $15-20 \%$ da matéria seca para as estruturas reprodutivas. O acúmulo de matéria seca em estruturas reprodutivas da

Richardia brasiliensis

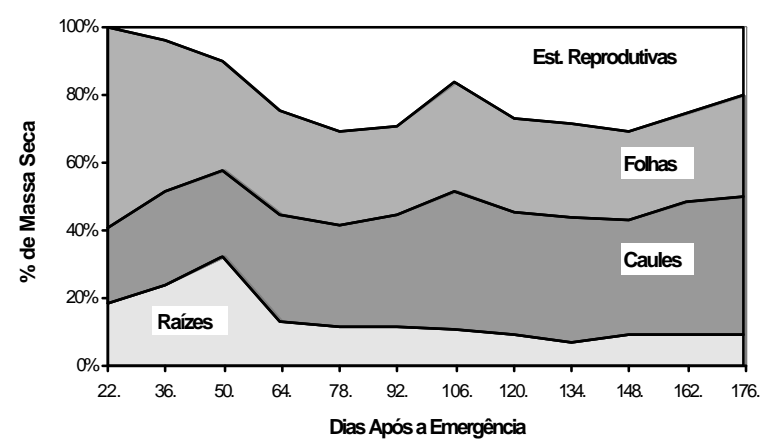

soja se iniciou em torno de 50 DAE e mantevese crescente até o final do ciclo, quando atingiu cerca de $50 \%$ do total.

Duas considerações devem ser efetuadas quanto ao comportamento: a planta daninha produziu e dispersou sementes ao longo do ciclo de desenvolvimento, sendo uma das principais características citadas por Baker (1974) para o sucesso de uma planta como infestante em campos agrícolas; e a soja, durante o processo de domesticação, perdeu a capacidade de dispersar suas sementes, produzindo acúmulo contínuo até o final do seu ciclo. Outra característica interessante da poaia-branca foi o incremento inicial na alocação de biomassa no sistema radicular, provavelmente para melhor fixação da planta e contato com os nutrientes por interceptação radicular.

Também é importante destacar que, após o início do processo reprodutivo efetivo, a poaia-branca manteve um equilíbrio na alocação de recursos para as diferentes partes da planta até o final do ciclo. Ou seja, as folhas, principal parte na produção de fotossintatos, perdem rapidamente sua participação a partir da sétima semana de crescimento. Essa inversão, para espécies daninhas, também foi relatada por Gravena et al. (2002) para Hyptis suaveolens, por Erasmo et al. (1997) para Senna obtusifolia, por Andreani Junior (1995) para Acanthospermum hispidum e por Rodrigues (1992) para Commelina benghalensis.

Nas Figuras 2 e 3 é possivel observar as diferenças nos teores de macronutrientes

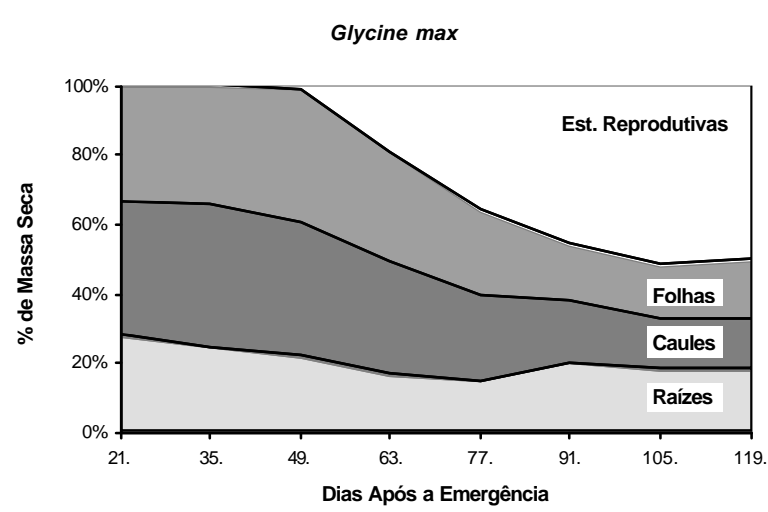

Figura 1 - Percentual da biomassa seca de Richardia brasiliensis e de soja distribuídas em raízes, caules, folhas e estruturas reprodutivas ao longo do ciclo de desenvolvimento. Jaboticabal-SP, 2003. 
Teor Total de Nitrogênio, Cálcio e Potássio

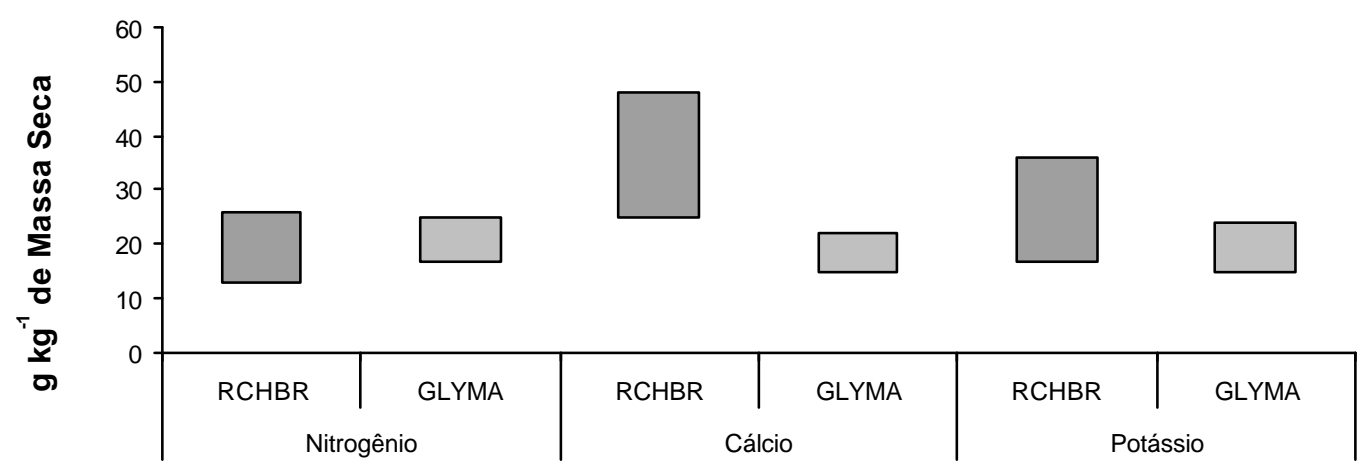

Figura 2 - Amplitude do teor total de nitrogênio, cálcio e potássio nas plantas de Richardia brasiliensis e Glycine max quando cultivadas em substrato de areia e irrigadas com solução nutritiva. Jaboticabal-SP, 2003.

Teor Total de Fósforo, Magnésio e Enxofre

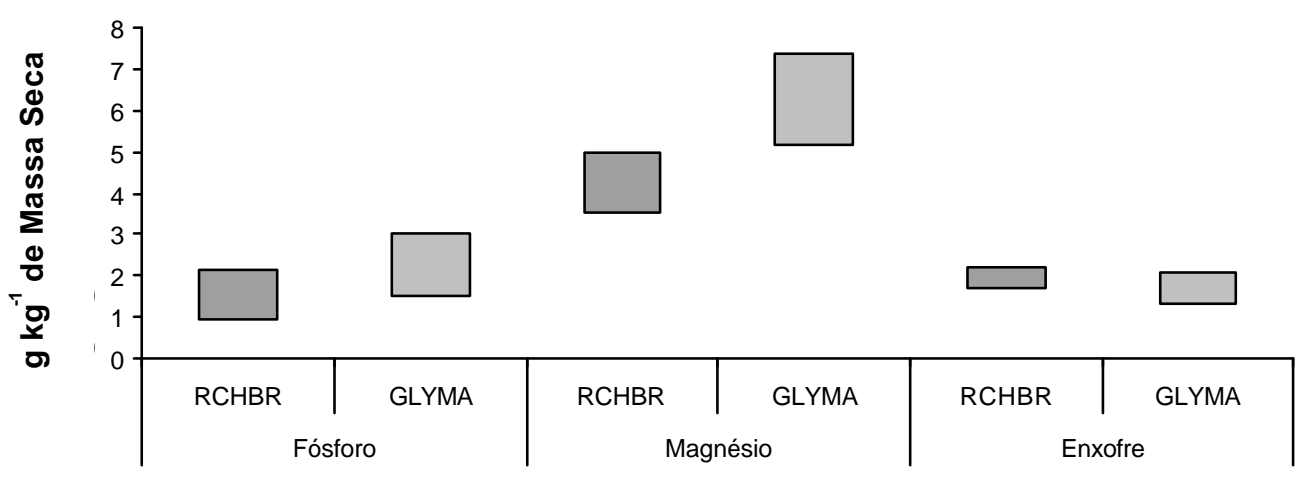

Figura 3 - Amplitude do teor total de fósforo, magnésio e enxofre nas plantas de Richardia brasiliensis e Glycine max quando cultivadas em substrato de areia e irrigadas com solução nutritiva. Jaboticabal-SP, 2003.

observados nas plantas de poaia-branca e de soja. As amplitudes dos valores das concentrações dos nutrientes avaliados durante o ciclo das plantas foram maiores, em soja, para fósforo, magnésio e enxofre. As amplitudes para nitrogênio, cálcio e potássio foram maiores em $R$. brasiliensis. Ao observar estas figuras, podese evidenciar uma maior adaptação da espécie daninha em relação à espécie cultivada. Essa diferenciação é notada principalmente nas variações de nitrogênio, cálcio e potássio, evidenciando uma adaptação da espécie daninha a solos com diferentes níveis de fertilidade.

Quanto ao acúmulo de biomassa e de macronutrientes para as duas espécies (Figura 4), o comportamento foi semelhante em cada espécie e diferente entre as espécies, tendo pontos de máximo acúmulo variando entre 96 e 127 DAE para a cultura da soja e de 138 e 147 DAE para a espécie daninha. Os pontos de inflexão ficaram em torno de 69 a 87 DAE para a cultura da soja e de 106 a 111 DAE para a planta daninha. A discrepância entre os valores observados para cada espécie é notada em todos os macroelementos analisados, porém é explicável quando se observam os pontos de máximo acúmulo de massa seca e o ciclo das duas plantas estudadas.

O acúmulo máximo de massa seca total se deu aos 104 DAE para a cultura da soja, com 
Richardia brasiliensis

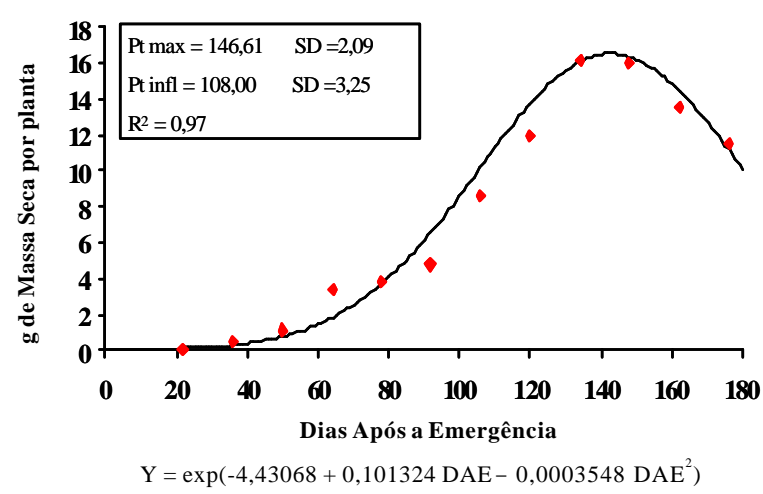

Glycine max

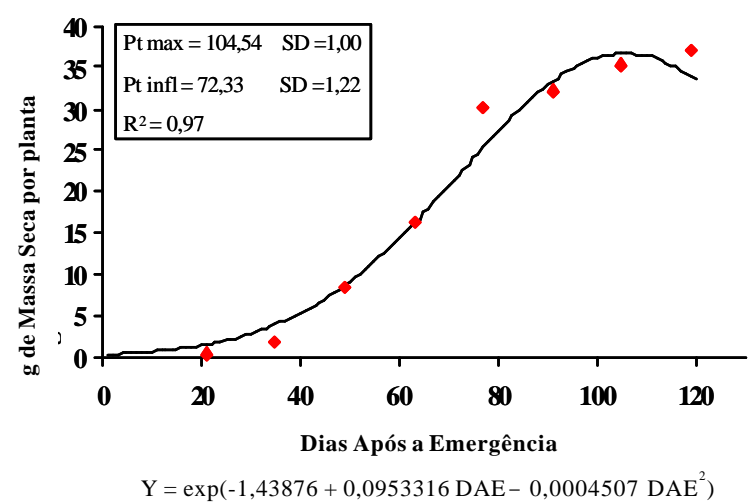

Figura 4 - Curvas de acúmulo de massa seca total para soja e poaia-branca, equações médias ajustadas com os respectivos coeficientes de determinação, seus pontos de máxima ( $\mathrm{Pt}$ max) e de inflexão ( $\mathrm{Pt}$ infl) e o desvio-padrão (SD) dos pontos estudados nas quatro repetições. Jaboticabal-SP, 2003.

o valor teórico de $35 \mathrm{~g}$ de massa seca por planta, e aos 146 DAE para R. brasiliensis, com o valor teórico de $17 \mathrm{~g}$ por planta, como pode ser observado na Figura 4. Este valor é inferior ao encontrado para outras plantas daninhas infestantes da cultura da soja, como Hyptis suaveolens (Gravena et al., 2002), Senna obtusifolia (Erasmo et al., 1997) e Commelina benghalensis (Rodrigues, 1992), quando considerado o período em que estas podem conviver com a cultura (0-148 DAE).

O valor do ponto de inflexão pode ser entendido como sendo o dia em que o acúmulo diário dos macronutrientes da planta chegou ao seu valor máximo, sendo a taxa de absorção diária crescente até esse momento: $70,69,87,77$, 78 e 74 DAE para N, P, K Ca, Mg e S, respectivamente, nas plantas de soja; e 108, 109, 107, 109, 106 e 111 DAE para N, P, K Ca, Mg e S, respectivamente, nas plantas de $R$. brasiliensis. Huett \& Dettman (1988) e Fayad et al. (2002) utilizaram o mesmo parâmetro para determinar o máximo acúmulo diário de macronutrientes em tomateiros, sendo relatado pelos últimos autores: 46, 39, 51, 45, 15 e 44 dias após o transplante das mudas para $\mathrm{N}, \mathrm{P}, \mathrm{K}, \mathrm{Ca}, \mathrm{Mg}$ e S, respectivamente.

É possível que as diferenças na taxa de absorção de um nutriente ao longo do ciclo de vida da planta sejam reguladas por um controle no tipo ou na atividade do transportador. Como exemplo, observa-se que o transporte ativo de $\mathrm{K}^{+}$ocorre quando ele está em concentrações externas muito pequenas, e o passivo (de baixa afinidade) ocorre quando há altas concentrações desse elemento. O tipo de transporte e a disponibilidade dos nutrientes no meio influenciam diretamente a taxa de absorção do elemento, que por sua vez afetará o acúmulo deste.

De modo geral, o máximo acúmulo diário dos nutrientes coincidiu com o período inicial de frutificação de ambas as espécies, como também observado por Fayad et al. (2002) em tomateiros. Nesse período ocorre o estabelecimento de uma força mobilizadora de nutrientes e assimilados, devido ao aumento da atividade metabólica, associada à atividade hormonal e à divisão e crescimento celular (Taiz \& Zeiger, 1995).

Para um valor médio de 78 DAE, das abcissas dos pontos de inflexão, para massa seca (Figura 1), nitrogênio, fósforo, potássio, cálcio, magnésio e enxofre (Figuras 5 a 10, respectivamente), observou-se, na curva média ajustada para a cultura da soja, um acúmulo de $25,9 \mathrm{~g}$ de massa seca; $615,6 \mathrm{mg}$ de $\mathrm{N} ; 77,2 \mathrm{mg}$ de P; 538,6 mg de K; 535,0 mg de Ca; $171,5 \mathrm{mg}$ de $\mathrm{Mg}$; e 39,5 mg de S, ao passo que, no mesmo período, uma planta de $R$. brasiliensis acumula $3,7 \mathrm{~g}$ de massa seca; $50,8 \mathrm{mg}$ de $\mathrm{N} ; 3,2 \mathrm{mg}$ de P; 104,4 mg de K; 127,8 mg de Ca; 18,8 mg de Mg; e 3,7 mg de S. 


\section{Richardia brasiliensis}

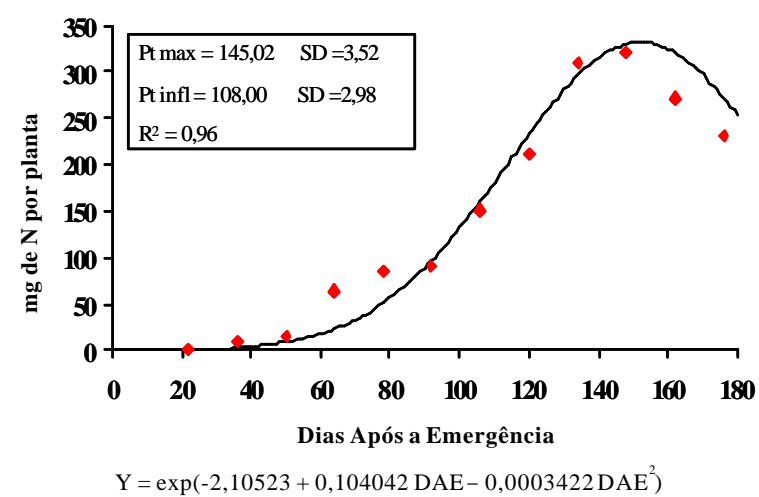

\section{Glycinemax}

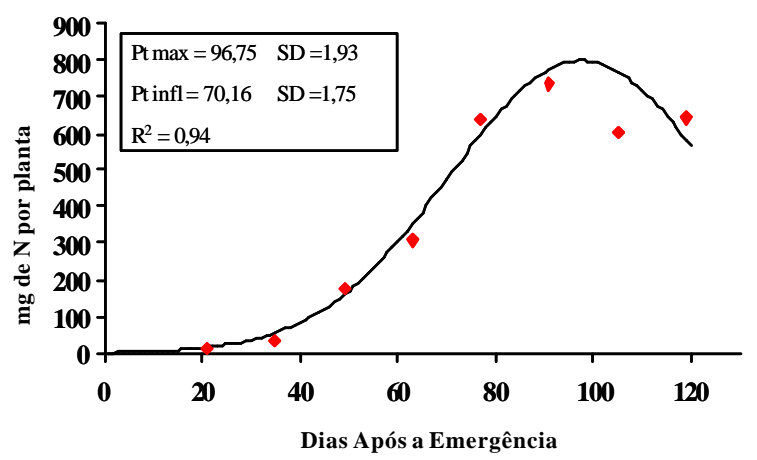

$\mathrm{Y}=\exp \left(-0,131018+0,134434 \mathrm{DAE}-0,0006894 \mathrm{DAE}^{2}\right)$

Figura 5 - Curvas de acúmulo total de nitrogênio para soja e poaia-branca, equações médias ajustadas com os respectivos coeficientes de determinação, seus pontos de máxima (Pt max) e de inflexão (Pt infl) e o desvio-padrão (SD) dos pontos estudados nas quatro repetições. Jaboticabal-SP, 2003.

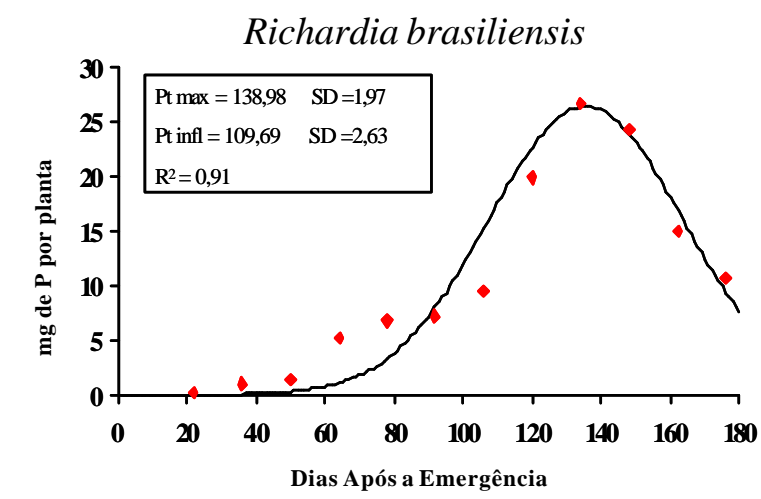

$\mathrm{Y}=\exp \left(-8,36217+0,1717585 \mathrm{DAE}-0,0006338 \mathrm{DAE}^{2}\right)$

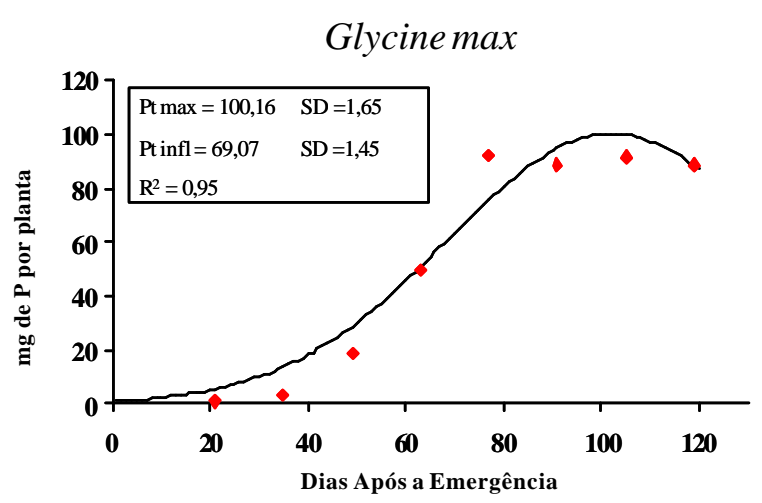

$\mathrm{Y}=\exp \left(-0,0122344+0,0903521 \mathrm{DAE}-0,000442 \mathrm{DAE}^{2}\right)$

Figura 6 - Curvas de acúmulo total de fósforo para soja e poaia-branca, equações médias ajustadas com os respectivos coeficientes de determinação, seus pontos de máxima (Pt max) e de inflexão (Pt infl) e o desvio-padrão (SD) dos pontos estudados nas quatro repetições. Jaboticabal-SP, 2003.

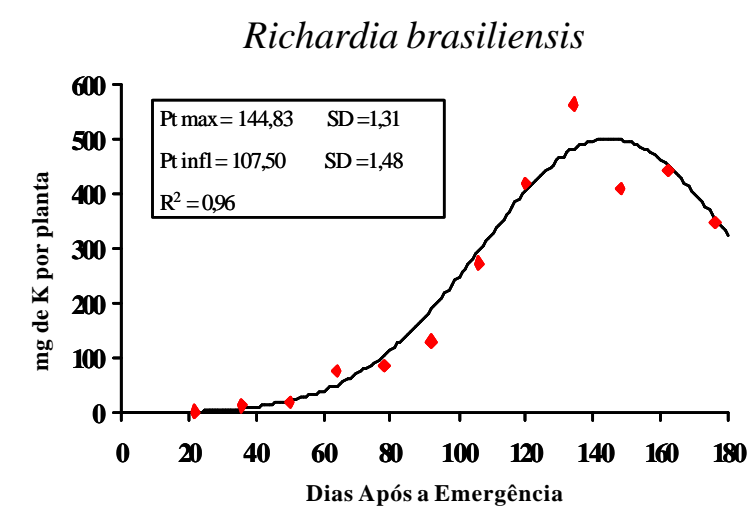

$\mathrm{Y}=\exp \left(-1,162575+0,1011996 \mathrm{DAE}-0,0003525 \mathrm{DAE}^{2}\right)$
Glycine max

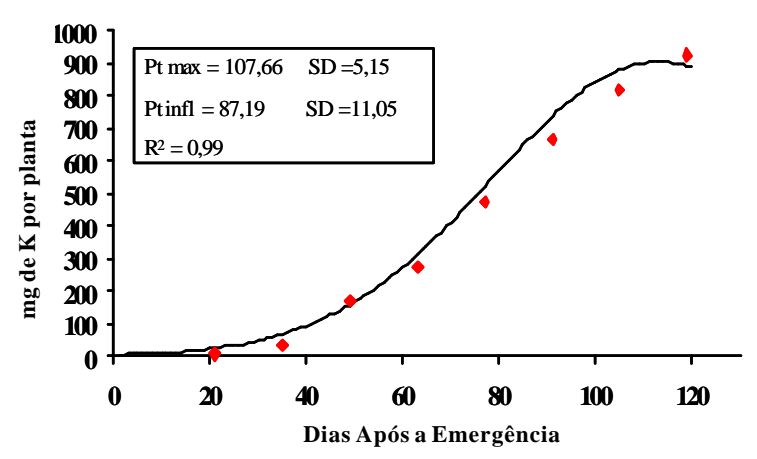

$\mathrm{Y}=\exp \left(-1,40323+0,0955927 \mathrm{DAE}-0,0004225 \mathrm{DAE}^{2}\right)$

Figura 7 - Curvas de acúmulo total de potássio para soja e poaia-branca, equações médias ajustadas com os respectivos coeficientes de determinação, seus pontos de máxima (Pt max) e de inflexão (Pt infl) e o desvio-padrão (SD) dos pontos estudados nas quatro repetições. Jaboticabal-SP, 2003. 


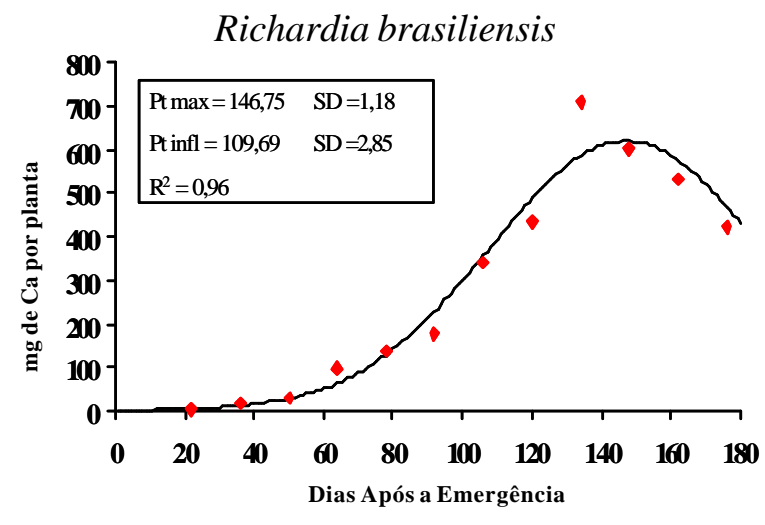

$\mathrm{Y}=\exp \left(-0,750225+0,0977604 \mathrm{DAE}-0,0003328 \mathrm{DAE}^{2}\right)$

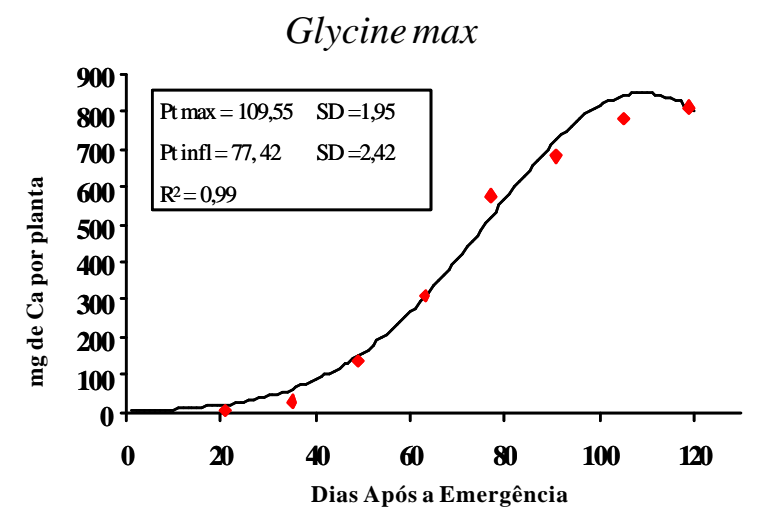

$\mathrm{Y}=\exp \left(-1,046653+0,104423 \mathrm{DAE}-0,0004782 \mathrm{DAE}^{2}\right)$

Figura 8 - Curvas de acúmulo total de cálcio para soja e poaia-branca, equações médias ajustadas com os respectivos coeficientes de determinação, seus pontos de máxima (Pt max) e de inflexão (Pt infl) e o desvio-padrão (SD) dos pontos estudados nas quatro repetições. Jaboticabal-SP, 2003.
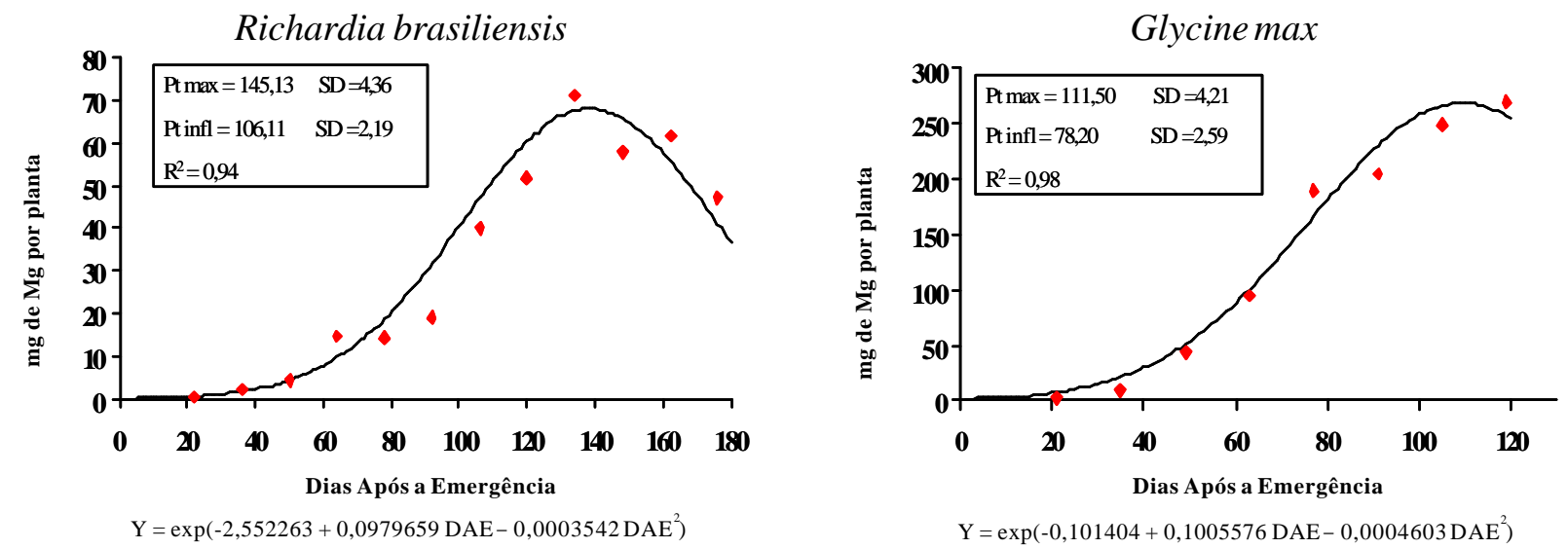

Figura 9 - Curvas de acúmulo total de magnésio para soja e poaia-branca, equações médias ajustadas com os respectivos coeficientes de determinação, seus pontos de máxima (Pt max) e de inflexão (Pt infl) e o desvio-padrão (SD) dos pontos estudados nas quatro repetições. Jaboticabal-SP, 2003.

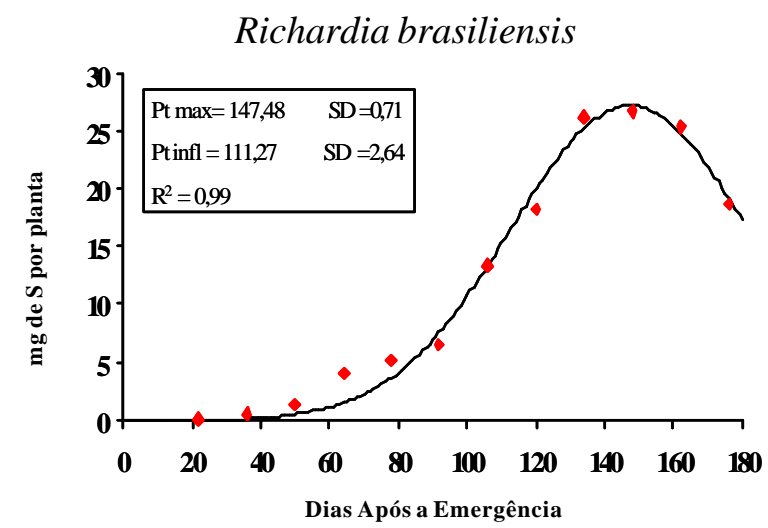

$\mathrm{Y}=\exp \left(-5,749265+0,122984 \mathrm{DAE}-0,0004178 \mathrm{DAE}^{2}\right)$

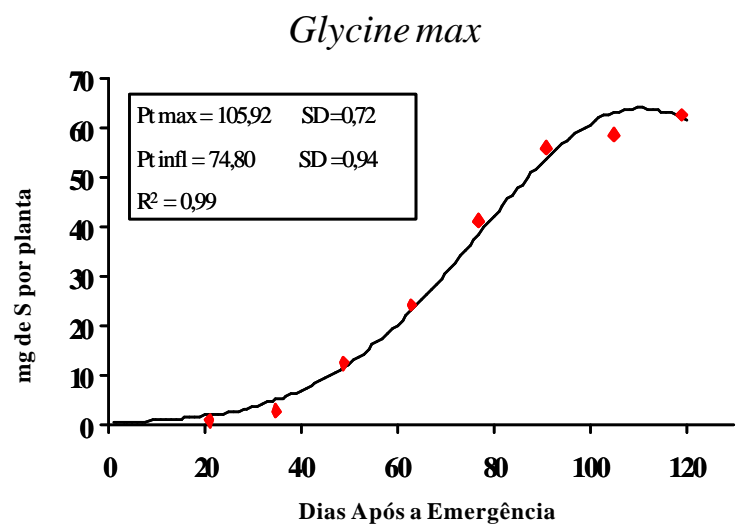

$\mathrm{Y}=\exp \left(-1,35823+0,0997002 \mathrm{DAE}-0,0004506 \mathrm{DAE}^{2}\right)$

Figura 10 - Curvas de acúmulo total de enxofre para soja e poaia-branca, equações médias ajustadas com os respectivos coeficientes de determinação, seus pontos de máxima (Pt max) e de inflexão (Pt infl) e o desvio-padrão (SD) dos pontos estudados nas quatro repetições. Jaboticabal-SP, 2003. 
Com base nas observações feitas durante os ensaios e nos dados apresentados, é possivel concluir que após os 50 DAE existe uma inversão na representatividade das folhas por caules, para a espécie daninha, e por caules e posteriormente por estruturas reprodutivas, para a soja. A taxa 1de acúmulo diário dos macronutrientes atingiu seus maiores valores entre 69 e 87 DAE para a soja e 106 e 111 DAE para poaia-branca.

Levando em conta a média dos valores de pontos de inflexão observados para a soja, temse que aos 78 DAE ela acumula mais massa seca e nutrientes do que a planta daninha, no mesmo período.

\section{LITERATURA CITADA}

AGRIANUAL - Anuário da Agricultura Brasileira. São Paulo: FNP Consultoria \& Comércio. 2000. 546 p.

ANDREANI JUNIOR, R. Estudos sobre a dormência das sementes, o crescimento e a absorção de macronutrientes por plantas de Acantospermum hispidum DC. 1995. $72 \mathrm{f}$. Tese (Mestrado em Agronomia) - Universidade Estadual de São Paulo, Jaboticabal, 1995.

BAKER, H. The evolution of weeds. Econ. Bot., v. 37, p. 255-282, 1974.

BARBOSA JUNIOR, A. F. Crescimento, marcha de absorção e distribuição de macronutrientes deRottboelia exaltata L. 2001. 66 f. Monografia (Trabalho de Graduação em Agronomia) - Universidade Estadual Paulista, Jaboticabal, 2001.

BARROS, A. C. et al. Avaliação de herbicidas no controle de plantas daninhas na cultura de soja. Planta Daninha, v. 10, n. $1 / 2$, p. $45-49,1992$.

BLANCO, H. G. et al. Observações sobre o período em que as plantas daninhas competem com a soja [Glycine Max (L.) Merrill]. O Biológico, v. 39, n. 2, p. 31-35, 1973.

BLANCO, H. G.; OLIVEIRA, D. A.; ARAÚJO, J. B. M. Período crítico de competição de uma comunidade natural de mato em soja [Glycine Max (L.) Merrill]. In:

SEMINÁRIO NACIONAL DA PESQUISA DE SOJA, 1 ., 1978, Londrina . Anais... Londrina: EMBRAPA-CNPSO, 1978. p. 151-157.
CARVALHO, F. T. Integração de práticas culturais e dosagens de herbicidas aplicados em pós- emergência, no controle de plantas daninhas e produtividade de cultura de soja [Glycine max (L.) Merrill]. 1993. $94 \mathrm{f}$.

Dissertação (Mestrado em Agronomia) - Universidade Estadual Paulista, Jaboticabal, 1993.

CARVALHO F. T.; VELINI, E. D. Períodos de interferência das plantas daninhas na cultura da soja. I - Cultivar IAC 11. Planta Daninha, v. 19, n. 3, p. 317-322, 2001.

DURIGAN, J. C. et al. Período de matocompetição na cultura da soja [Glycine Max (L.) Merrill], cultivares Santa Rosa e IAC 2.1 - Efeitos sobre os parâmetros de produção. Planta Daninha, v. 6, n. 2, p. 86-100, 1983.

ERASMO, E. A. L.; BIANCO, S.; PITELLI, R. A. Estudo sobre o crescimento de fedegoso. Planta Daninha, v. 15, n. 2, p. 170-179, 1997.

FAYAD, J. A. et al. Absorção de nutrientes pelo tomateiro cultivado sob condições de campo e de ambiente protegido. Hort. Bras., v. 20, p. 90-94, 2002.

GRAVENA, R. et al. Análise do crescimento de Hyptis suaveolens. Planta Daninha, v. 20, n. 2, p. 189-196, 2002.

HOAGLAND, D. R.; ARNON, D. J. The water culture method of growing plants without soil. Berkeley: University of California, 1950.

HUETT, D. O.; DETTMAN, B. Effect of N on growth, fruit quality and nutrient uptake of tomatoes grown in sand culture. Aust. J. Exp. Agric., v. 28, p. 391-399. 1988.

KISSMANN, K. G. Plantas infestantes e nocivas. São Paulo: BASF, 1995. T.3.

PITELLI, R. A. Interferência de plantas daninhas em culturas agrícolas. Inf. Agropec., v. 11, p. 16-27, 1985.

RODRIGUES, B. N. Estudos sobre a dormência, absorção de macronutrientes e resposta a calagem por Commelina bengalensis L. 1992. 129 f. Tese (Doutorado em Agronomia) - Universidade Estadual de São Paulo, Jaboticabal, 1992.

TAIZ, L.; ZEIGER, E. Plant physiology. California: The Benjamin/Cummigs Publishing, 1995. 559 p. 